\title{
MAPK and AKT Pathway Intersection in Neuroblastoma Cells
}

\author{
Aysegul Yildiz ${ }^{1 *}$ and Ozgur Tanriverdi ${ }^{2,3}$ \\ ${ }^{1}$ Department of Molecular Biology and Genetics, Muğla Sitkı Koçman University, Turkey \\ ${ }^{2}$ Molecular Biology and Genetics, Muğla Sitkı Koçman University, Turkey \\ ${ }^{3}$ Department of Medical Oncology, Muğla Sıtkı Koçman University, Turkey
}

Submission: February 07, 2017; Published: March 09, 2017

"Corresponding author: Aysegul Yildiz, Faculty of Science, Department of Molecular Biology and Genetics, Mugla Sitki Kocman University, Kötekli, Mugla 48000, Turkey, Tel: +90 252211 5412; Fax: +90 0252211 1472; Email: aysegulunal@mu.edu.tr

\begin{abstract}
One of the most important contributing factors for cancer development is the aberrant activation of mitogenic MAPK and AKT survival pathways. Abnormal activities of these pathways also indicates poor prognosis as a result of drug resistance in cancer treatment. It is revealed that there is a cross-talk between these two signaling cascades and they act together by one triggering the other performing an anti-apoptotic effect. It is evident that interplay between MAPK and AKT pathways is at the center of poor prognosis especially in neuroblastoma. However, it is still unknown what is there at the heart of this interaction. In this mini review, tumorigenic and chemotherapy-resistant effects of MAPK and AKT pathways and also the effect of their cross-talk in neuroblastoma and other cancers is summarized, Then, several cross-talk nodes between two pathways, which is used by the cells in a context-dependent mode is briefly explained. Finally, summarizing the studies giving insights about certain cell cycle regulators which may be involved in the intersection of these signaling pathways, importance of analyzing not only direct crosstalk between the members of these two pathways, but also mediator-dependent interactions are emphasized, since it is crucial to understand these interactions to choose the appropriate molecular targets for both diagnosis and treatment especially of neuroblastoma which has a very poor prognosis.
\end{abstract}

Keywords: Neuroblastoma, Drug-resistance, MAPK, MEK, AKT, PI3K

\section{Short Communication}

Neuroblastoma is one of the most frequently seen pediatric extra cranial solid tumor and $98 \%$ of patients are under ten years old but it is among uncommon malignancies in adults [1]. It has a very poor prognosis that long-term survival ratio is only $30 \%[2,3]$. Since it originates from migrating neural crest cells, neuroblastomas arise in peripheral nervous system. The reason for neuroblastoma to be both genotypically and phenotypically very hetero genious is its neural crest origin which has the potential of differentiating into various types of tissue and cell types. The most significant determinants of the disease are spontaneous genetic alterations such as oncogenic activation, deregulation of mitogenic and survival pathways and chromosomal anomalies [4,5].

Phosphatidylinositol3-kinase/protein kinase-B/mammalian target of rapamycin (PI3K/AKT/mTOR or AKT) signaling pathway is one of the most emerging intracellular mechanisms that is found to be over-activated in many types of cancers $[6,7]$. AKT pathway may have apoptotic or cancerogenic functions by taking role in mitosis, differentiation, cellular metabolism and cellular cytoskelatal organization. Bringing this multifunctional feature of AKT pathway into focus, it is thought that pathological AKT over-activation may result in tumor genesis and resistance against anti-cancer therapies. Thus, AKT is one of the most striking targets of cancer studies [8,9]. Especially, there are critical gain of function mutations causing over-activation of AKT pathway, mostly seen in mTOR gene which is the target for some approved drugs such as everolimus and temsirolimus to inhibit over-activity of AKT pathway [10].

Neuroblastoma cells, like many cancer cells, has overactivated AKT pathway $[11,12]$. Studies with neuroblastoma cell lines showed that using AKT-specific inhibitors drive these cancerous cells through apoptosis $[13,14,15]$. Besides, positive correlation between poor prognosis and pathological AKT activation has also been shown by in vivo studies [16]. By taking the importance of AKT pathway in neuroblastoma pathogenesis into account, studies on specific AKT-inhibitors continue intensely in pre-clinical stages. In one of these studies, it was shown that thioredoxin 1 , a small ubiquitous protein with various cellular functions, is over-expressed in many cancerous cell lines, including neuroblastomas [17]. This small protein is found to regulate cell growth proteins like PTEN (Phosphatase 
and Tensin homolog) and AKT and its induction is shown to cause oncogenicity [18]. Thus, thioredoxin 1 is thought to be a potential target for therapeutic intervention [19].

Another signaling pathway that has an important role in tumor genesis and drug-resistance, such as the AKT signaling pathway, is the mitogen-activated protein kinase (MAPK) signaling pathway $[20,21]$. The MAPK is one of the highly conserved signaling pathways within the cell that allows cells to respond to environmental stimuli and stress [22]. The signal generated by the received stimuli is primarily transferred to the small oncogenic G-protein Ras and then to the Raf (MEK Kinase) protein, which in turn activates MEK 1/2 (MAPK / ERK Kinase or MAP Kinase Kinase) signaling proteins. The active MEK1/2 activates ERK1/2 by phosphorylation and controls cellular events such as differentiation, cleavage, progression of cell cycle and apoptosis [23]. Thus, abnormalities in the MAPK signaling pathway can lead to very different results from apoptosis to cancer formation [24,25]. However, little is known about the role of this signaling pathway in neuroblastoma cancer. There are only a few studies suggesting that this signaling pathway has a role in neuroblastoma cells transforming into the transformed phenotype and acquiring drug-resistance [21].

Nowadays, immune-check-point inhibitors and molecular targeted anti-cancer drugs as well as chemotherapeuticals are the most important current approaches in cancer treatment, since they have provided an impressive progression-free survival and/or overall survival advantage in various advancedstage cancer. However, drug-resistance may be one of the most important reasons overshadowing this clinical success. Although previous studies indicate that MAPK and AKT signaling pathways have played an important role for drug-resistance in anti-cancer therapies, including examples such as; an innate drug resistance shown in lung cancer cells for anti-EGFR (epidermal growth factor receptor) treatment, a computational model study of drug-resistance for BRAF inhibitors such as dabrafenib and vemurafenib in advanced malignant melanoma, microtubuletargeted drug resistance shown in patients with prostate cancer as well as etoposide-related drug resistance in neuroblastomas, the mechanism of interaction between these pathways still remains unclear [26-29]. However, the role of triggering and aberrant activation of MAPK (mitogenic) and AKT (survival) signaling pathways cannot be ignored in the pathogenesis of neuroblastoma and many other cancer types. These signaling pathways also lead to the formation of chemotherapeutic resistance during the treatment process and to a considerable reduction in the effectiveness of the treatment. Under normal cell conditions, it has been understood that these two signaling pathways act in communication and interaction with each other, not independently of each other, and that any of the two signaling pathways can inhibit or activate the other depending on the circumstances [30]. The contribution of abnormal behavior of both signaling pathways to proliferation and survival of cancerous cells suggests that this interaction may also play a role in the formation and progression of neuroblastoma. Thus, rather than separately focusing on these two pathways, it will be more effective to study the interplay between them. However, this possible interaction and its focus on the molecular level have not yet been elucidated in the neuroblastoma cells, which will be valid for all cancer types of this interaction.

When we look at the interaction between the members of two pathways, there are several cross-talk nodes which are used by the cells in a context-dependent mode. A major cross-talk node is at the level of Phosphatidylinositol [3,4,5] P3-mediated Ras GEF and RasGAP signalling. Another PI3K $\rightarrow$ ERK cross-talk node include PI3K-induced Raf and MEK stimulation. Whereas crosstalk interactions resulting from PI3K activation and mediated by PDK1 activate the Ras/MAPK pathway, Akt and its downstream effectors, mTOR and p70S6K, affect ERK signalling, negatively [30]. On the other side, active ERK can influence the PI3K/Akt pathway via several interaction routes. One mechanism involves the modulation of the tyrosine phosphorylation level by ERK mediated phosphorylation at serine and threonine residues of certain AKT members [31]. Yet, multiple signaling routes and nodes involved in Ras/MAPK $\rightarrow \mathrm{PI} 3 \mathrm{~K} / \mathrm{Akt}$ cross-talk make it context dependent.

At this point, while trying to figure out the factors involved in the intersection of these two signal paths, some points that can shed light on this intersection are striking. Not only direct interaction between the members of these two pathways, but also mediator-dependent interactions, independent from both pathways' members, should be considered, since there are studies giving insights about certain cell cycle regulators which may be involved in the intersection of these signaling pathways. It has been shown that over-activity or over-expression of some cell cycle regulators such as Speedy/RINGO, a novel cell cycle regulator, cause cells to become cancerous and become aggressive by escaping them from apoptosis [32,33]. Moreover, a previous study showed that neurodegeneration and subsequent neuronal death can be prevented by utilizing this anti-apoptotic effect of Speedy/RINGO in degenerating hippocampal neurons [34]. The results clearly demonstrate that the Speedy/RINGO protein expression in degenerating neurons leads to an increase in CDK2 expression, while leading to a decrease in p27Kip1 expression. As a result, the decrease observed at apoptotically active caspase-3 level was confirmed, so that the ability of the Speedy/RINGO to escape cells from apoptosis was demonstrated in degenerating neurons. By this means, the authors have confirmed this cell cycle regulator's apoptosis-defying effect in a very different context.

Yet, it has been shown that just as AKT over-expression, over-expression of Speedy/RINGO results in chemotherapy resistance [3]. If this is the case, it is crucial to figure out a potential interaction between Speedy/RINGO and AKT pathway.

Besides, a few studies about the development of breast tissue and tumorigenesis showed that MAPK pathway over- 
activation results in Speedy/RINGO over-expression and if MEK1 enzyme, a member of MAPK pathway is inhibited, Speedy/ RINGO expression is shown to be decreased.

On the other hand, studies on testis tissue showed that overexpression of Speedy/RINGO protein causes an increase in cell cycle regulators Cyclin A2-CDK2 expression. Mouse embryonic stem cell studies revealed that Cyclin A2-CDK2 complex has an important role in AKT hyper-phosphorylation which is one of the most effective factors causing chemotherapy resistance in many cancer types [35]. In all of the above mentioned studies, connection of Speedy/RINGO and other potent cell cycle regulators with AKT and MAPK pathways is studied partially rather than analyzing them all together for a possible interaction. Besides, all the studies are performed in cancers other than neuroblastoma.

In this manner, the main question should be that: May the primary underlying reason for aberrant activation of wellknown cancer triggering AKT and MAPK pathways be the overexpression of certain cell cycle regulators such as Speedy/RINGO or any other mediator protein that provides interaction between these two pathways?

As already mentioned likewise aberrant activation of MAPK and AKT signaling pathways, over-expression of certain cell cycle regulators such as Speedy/RINGO escapes cells from apoptosis and makes the chemotherapeutic response more difficult. Considering this similar apoptosis-defying effect of MAPK/AKT abnormal activation and the cell cycle regulator Speedy/RINGO over-expression, the potential cell cycle regulators that may be involved in the intersection of these two signal paths need to be addressed. It is very plausible to predict an interaction between cell cycle regulators and mitotic/survival pathways, since they are all interrelated because of serving at similar purposes in the cell. It is very important to understand which molecules are able to be effective in pathogenesis of cancer and also in correctly selecting molecular targets underlying the disease so that appropriate cancer treatments can be planned. In this direction, in our laboratory, we have an ongoing study aiming to get information about the connecting function of Speedy/RINGO in between AKT and MAPK pathways in neuroblastoma cells. Thus, it is vital to understand the interactions between different intracellular mechanisms and to choose the appropriate molecular targets for both diagnosis and treatment especially of neuroblastoma which has a very poor prognosis.

\section{References}

1. Esiashvili N, Goodman M, Ward K, Marcus RB, Johnstone PA (2007) Neuroblastoma in adults: Incidence and survival analysis based on SEER data. Neuroblastoma in adults: Incidence and survival analysis based on SEER data. Pediatr Blood Cancer 49(1): 41-46.

2. Maris JM (2010) Recent advances in neuroblastoma. N Engl J Med 362(23): 2202-2211.

3. Lubanska D, Porter LA (2014) The atypical cell cycle regulator Spy1 suppresses differentiation of the neuroblastoma stem cell population.
Oncoscience 1(5): 336-348.

4. Kaneko Y, Kanda N, Maseki N, Sakurai M, Tsuchida Y, et al. (1987) Different karyotypic patterns in early and advanced stage neuroblastomas. Cancer Res 47(1): 311-318.

5. Tanaka T, Slamon DJ, Shimoda H, Waki C, Kawaguchi Y, et al. (1988) Expression of Ha-ras oncogene products in human neuroblastomas and the significant correlation with a patient's prognosis. Cancer Res 48(4): 1030-1034.

6. Liu P, Cheng H, Roberts TM, Zhao JJ (2009) Targeting the phosphoinositide 3-kinase pathway in cancer. Nat Rev Drug Discov 8(8): 627-644.

7. Janku F (2012) PTEN assessment and PI3K/mTOR inhibitors: importance of simultaneous assessment of MAPK pathway aberrations. J Clin Oncol 30(Supplement).

8. Engelman JA (2009) Targeting PI3K signalling in cancer: opportunities, challenges and limitations. Nat Rev Cancer 9(8): 550-562.

9. Burris HA (2013) Overcoming acquired resistance to anticancer therapy: focus on the PI3K/AKT/mTOR pathway. Cancer Chemother Pharmacol 71(4): 829-842.

10. Polivka J, Janku F (2014) Molecular targets for cancer therapy in the PI3K/AKT/mTOR pathway. Pharmacology \& Therapeutics 142(2): 164-175.

11. Fang CX, Yang X, Sreejayan N (2007) Acetaldehyde promotes rapamycin-dependent activation of $\mathrm{p} 70(\mathrm{~S} 6 \mathrm{~K})$ and glucose uptake despite inhibition of Akt and mTOR in dopaminergic SH-SY5Y human neuroblastoma cells. Exp Neurol 203: 196-204

12. Fleming JM, Desury G, Polanco TA (2006) IGF-I and epidermal growth factor receptors recruit distinct upstream signalling molecules to enhance AKT activation in mammary epithelial cells. Endocrinology 14(12)7: 6027-6035.

13. Efron PA, Chen MK, Iyengar M (2006) Differential response of neuroblastoma cells to TRAIL is independent of PI3K/AKT. J Pediatr Surg 41:1072-1080.

14. Kim S, Kang J, Qiao J, Thomas RP, Evers BM, et al. (2004) Phosphatidylinositol 3-kinase inhibition down-regulates survivin and facilitates TRAIL-mediated apoptosis in neuroblastomas. J Pediatr Surg 39(4): 516-521.

15. Ruffels J, Griffin M, Dickenson JM (2004) Activation of ERK1/2, JNK and PKB by hydrogen peroxide in human SH-SY5Y neuroblastoma cells: role of ERK1/2 in H2O2-induced cell death. Eur J Pharmacol 483(2-3): 163-173.

16. Opel D, Poremba C, Simon T (2007) Activation of Akt predicts poor outcome in neuroblastoma. Cancer Res 67(2): 735-745.

17. Andoh T, Chock PB, Chiueh CC (2002) The roles of thioredoxin in protection against oxidative stress-induced apoptosis in SH-SY5Y cells. J Biol Chem 277(12): 9655-9660.

18. Meuillet EJ, Mahadevan D, Berggren M, Coon A, Powis G (2004) Thioredoxin-1 binds to the C2 domain of PTEN inhibiting PTEN's lipid phosphatase activity and membrane binding: a mechanism for the functional loss of PTEN's tumor suppressor activity. Arch Biochem Biophys 429(2): 123-133.

19. Sartelet H, Rougemont AL, Fabre M (2011) Activation of the phosphatidylinositol 3'-kinase/AKT pathway in neuroblastoma and its regulation by thioredoxin 1. Human Pathology 42(11): 1727-1739

20. Guan J, Chen XP, Zhu H, Luo SF, Cao B, et al. (2004) Involvement of extracellular signal- regulated kinase/mitogen-activated protein kinase pathway in multidrug resistance induced by HBx in hepatoma cell line. World J Gastroentero 10(23): 3522-3527. 
21. Mattingly RR, Milstein ML, Mirkin BL (2001) Down-regulation of growth factor-stimulated MAP kinase signaling in cytotoxic drugresistant human neuroblastoma cells. Cell Signal 13(7): 499-505.

22. Kolch W (2000) Meaningful relationships: the regulation of the Ras/ Raf/MEK/ERK pathway by protein interactions. Biochem J 351: 289305.

23. Chang L, Karin M (2001) Mammalian MAP kinase signalling cascades. Nature 410(6824): 37-40.

24. Giroux S, Tremblay M, Bernard D, Cardin-Girard JF, Aubry S, et al (1999) Embryonic death of Mek1- deficient mice reveals a role for this kinase in angiogenesis in the labyrinthine region of the placenta. Curr Bio 9: 369-372.

25. Simon C, Hicks MJ, Nemechek AJ, Mehta R, O’Malley BW, et al. (1999) PD098059, an inhibitor of ERK1 activation, attenuates the in vivo invasiveness of head and neck squamous cell carcinoma. Br J Cancer 80: 1412-1419.

26. Marengo B, De Ciucis CG, Ricciarelli R, Furfaro AL, Colla R, et al (2013) p38MAPK inhibition: a new combined approach to reduce neuroblastoma resistance under etoposide treatment. Cell Death and Disease 4: e589.

27. Lassen A, Atefi M, Robert L, Wong DJL, Cerniglia M, et al. (2014) Effects of AKT inhibitor therapy in response and resistance to BRAF inhibition in melanoma. Molecular Cancer 1186/1476-4598-13-83

28. Liu Z, Zhu G, Getzenberg RH, Veltri RW (2015) The Upregulation of PI3K/Akt and MAP Kinase Pathways is Associated with Resistance of Microtubule-Targeting Drugs in Prostate Cancer. I Cell Biochem 116(7): 1341-1349.

29. Phuchareona J, McCormickb F, Eisele DW, Tetsua O (2015) EGFR inhibition evokes innate drug resistance in lung cancer cells by preventing Akt activity and thus inactivating Ets-1 function. PNAS, E3855-E3863.

30. Aksamitiene E, Kiyatkin A, Kholodenko BN (2012) Cross-talk between mitogenic Ras/MAPK and survival PI3K/Akt pathways: a fine balance. Biochem Soc Trans 40(1): 139-146.

31. Lehr S, Kotzka J, Avci H, Sickmann A, Meyer, et al. (2004) Identification of major ERK-related phosphorylation sites in Gab1. Biochemistry 43(38): 12133-12140.

32. McAndrew CW, Gastwirt RF, Donoghue DJ (2009) The atypical CDK activator Spy1 regulates the intrinsic DNA damage response and is dependent upon p53 to inhibit apoptosis. Cell Cycle 8: 66-75.

33. Gastwirt RF, Slavin DA, McAndrew CW, Donoghue DJ (2006) Spy1 expression prevents normal, cellular responses to DNA damage: Inhibition of apoptosis and checkpoint activation. J Biol Chem 281(46): 35425-35435.

34. Yildiz-Unal A, Korulu S, Karabay A (2012) SpeedyRINGO Inhibits Calpain-Directed Apoptosis in Neurons. J Alzheimer's Dis 31(4): 779791

35. Liu P, Begley M, Michowski W (2014) Cell-cycle-regulated activation of Akt kinase by phosphorylation at its carboxyl terminus. Nature 508: 541-545.

\section{Your next submission with Juniper Publishers will reach you the below assets}

- Quality Editorial service

- Swift Peer Review

- Reprints availability

- E-prints Service

- Manuscript Podcast for convenient understanding

- Global attainment for your research

- Manuscript accessibility in different formats

(Pdf, E-pub, Full Text, Audio)

- Unceasing customer service

Track the below URL for one-step submission https://juniperpublishers.com/online-submission.php 